\title{
Die Narratiewe Funksie van die Liedere in Openbaring 4:1-5:15
}

J A du Rand

\section{Abstract}

\section{The Narralological Function of the Hymns in Revelation 4:1-5:15}

The problem is that research on the hymns in the book of Revelation has concentrated up till now one-sidedly on pre-textual issues and internal structure. Narrative criticism is recently proving that the Apocalypse could be treated as a full literary text. The application of narratological insights on plot development, focalisation/point of view and reader response as well as employing some insights from the socio-cultural milieu enables the text as dramatic narrative to deliver its own message even more dynamically. The function of the hymns in chapters 4 and 5 is to confirm the identity of God and the Lamb, as well as that of the reader/hearer within a narratological framework.

\section{Oriënterend: Wanneer is 'n lied 'n lied?}

In resente navorsing oor die boek Openbaring word dit al hoe meer verstaan as ' $n$ unieke narratief met bepaalde literêre en estetiese eienskappe. ${ }^{1}$ Verdere navorsing oor die toepasbaarheid van narratiewe modelle en - metodes op die literêre analise van die boek Openbaring beleef tans 'n bloei- maar ook 'n oorgangsfase. Gedurende die afgelope 16 jaar is navorsing in dié verband hoofsaaklik toegespits op die sosiohistoriese aangeleenthede, dit wil sê die sosiale situasie waarin die historiese eerste lesers hulle bevind het en van waaruit die teks gegroei het, asook die tipiese van die apokoliptiese genre ${ }^{2}$.

Dit het meegebring dat studies oor die liedere eensydig gekonsentreer het op die voortekstuele konteks, interne opbou en die teologiese bydrae van die liedere. Die meeste navorsers het ook aanvaar dat die liedere funksioneer soos die koorsange in die Griekse dramas ${ }^{3}$. Op so 'n wyse is die liedere by voorbaat bestudeer as losstaande dele met 'n "geskiedenis".

Vanuit narratiewe perspektief reflekteer die liedere nie net betekenisvolle kommentaar op die visioene nie maar bewerkstellig dit ook leserbetrokkenheid in die vertelde wêreld. Die doel van hierdie artikel is om verdere navorsingsbane te betree betreffende die toepassing van die narratiewe metodologie op 'n analise van Openbaring, en spesifiek met betrekking tot die liedere in hoofstukke 4 en 5.

Die funksie van liedere het 'n opwindende geskiedenis in die Joods-Christelike tradisie. In die Hebreeuse Ou Testament gee die psalms byvoorbeeld uiting aan dankbaarheid en adorasie teenoor God wat deur sy magtige dade sy eiendom deur die geskiedenis heen begelei het. Psalm 9 is maar een tipiese voorbeeld daarvan. Onder die bekendste liedere in die Nuwe Testament tel Filippense 2:5-11; Efesiërs 5:19; Kolossense 1:15-20 en veral die Lukaanse reeks in hoofstukke 1-2. Sulke liedere speel in elke kontekstuele samehang 'n funksionele rol, sowel wat opbou as betekenis betref. 
Voordat die narratiewe funksie van die liedere in Openbaring 4-5 bepaal kan word, moet die vraag eers beantwoord word: Wat is 'n lied en op grond waarvan word 'n lied in Openbaring gekonstitueer? Oscar Culmann het reeds die hele drama van die eindtyd volgens Openbaring in die konteks van die vroeë Christelike erediens en aanbidding gesien ${ }^{4}$. Dit moet ook in gedagte gehou word dat Openbaring aanvanklik hardop voorgelees is in die gemeentelike aanbidding ${ }^{5}$. Die himniese element het in so ' $\mathrm{n}$ situasie dus ' $n$ besondere plek ingeneem. Tot so ' $n$ mate, volgens Shepherd, dat hy gemeen het dat die opbou van Openbaring verband hou met die vroeë kerk se paasliturgie ${ }^{6}$.

Dit laat die vraagstuk verdiep of die liedere in Openbaring direk in verband gebring kan word met die werklike liturgiese praktyke in die vroeë kerk. Anders gestel: Is die liedere losstaande toevoegings tot die teks op liturgiese oorwegings of is dit die skeppings van die outeur self? Laasgenoemde standpunt geniet die meerderheid steun ${ }^{7}$. Die liedere is kunstig en funksioneel op ' $n$ narratiewe organiese wyse vervleg in die narratief van Openbaring. Dit staan egter nie geheel en al los van die kultiese praktyke van die lesers asook die inhoud van die narratief nie. Ons moet egter onderskei tussen historiese en literêre vrae aan die teks.

Funksioneer die liedere in Openbaring op dieselfde wyse as die koorsange in die Griekse tragedies? Blevins onderskryf dié standpunt ${ }^{8}$ op voetspoor van Brewer en Bowman ${ }^{9}$ wat onderskei tussen individuele liedere in Openbaring (12:10-12;14:7, 8 , $9-11,15,18 ; 16: 5-6,7 ; 18: 2-3,4,20,21-24 ; 19: 18 ; 21: 3-4)$ en koorliedere (4:6v, 10v; $5: 9 v, 11 v, 13 ; 6: 9 v v, 15-17 ; 7: 9 v v, 11 ; 11: 15,16 v ; 15: 2-4 ; 18: 4-19 ; 19: 1 v v)$. Harris het egter oorwegend aangetoon dat dié teorie elemente van geldigheid bevat maar nie volledig water hou met betrekking tot Openbaring nie:

"The most obvious difference is the fact that the events in the Apocalypse are presented in prose form through a narrator, who is dramatized in the text as John, while events in Greek drama are presented through the medium of dialogue between characters usually two. Hence, the hymnic units, or odes, sung by the chorus in Greek drama are presented via free direct discourse and the hymnic units in the Apocalypse are presented by means of quoted speech"10.

'n Ander standpunt is dat die koorsang in Openbaring tog waardevolle kommentaar lewer op die gebeure in die dramatiese narratief ${ }^{11}$. Alhoewel die kore in die Griekse dramas ook kommentaar kan lewer op die gebeure, het dit dikwels eerder as nog ' $n$ karakter gefunksioneer en selfs die standpunte van die protagonis weerspreek. 'n Parallel tussen die kore in die Griekse dramas en die liedere in Openbaring kan dus nie sondermeer getrek word nie. Daarom is die indeling van liedere deur Brewer en Bowman op grond van só 'n parallel nie geldig nie.

In apokaliptiese briefliteratuur moet eerder gebruik gemaak word van kriteria in die teks self om die liedere te kan onderskei. Stilistiese kriteria kan onder andere die volgende insluit: die vorm van die werkwoord (byvoorbeeld in tweede of derde persoon), die gebruik van partikels, moontlike parallelismus membrorum, die voorkoms van strofes en anti-strofes, retoriese elemente soos byvoorbeeld inclusio, giasmes en antiteses en moontlike hapax legomena. Ko-tekstuele kriteria waarop gelet kan word is onder andere: die gebruik van inleidingsformules soos légo, die teenwoordigheid van elemente soos petisie aan die godheid om hulp en 'n gebed of lofprysing aan die einde van die lied. 
Jörns het 'n waardevolle bydrae gelewer deur op grond van 'n strofe/anti-strofe patroon die volgende liedere te onderskei: ${ }^{12}$

\section{Strofe}

$4: 9$

5:9B-10

$7: 10 \mathrm{~B}$

$11: 15$

$16: 5 \mathrm{~B}-6$

$19: 1 \mathrm{~B}-2$

$19: 5 \mathrm{~B}$

\section{Anti-strofe}

$4: 11$

$5: 12-13$

$7: 12$

$11: 17-18$

$16: 7 \mathrm{~B}$

$19: 3-4$

$19: 6 \mathrm{~B}-8$

Indien die genoemde stillistiese en ko-tekstuele kriteria in ag geneem word, tesame met Jönus se indeling volgens strofe en anti-strofe en 4:8;12:10-12 en 15:3 wat duidelik liedere is, kan die volgende gedeeltes in Openbaring as liedere onderskei word: 4:8-11; $5: 9-13 ; 7: 10-12 ; 11: 15-18 ; 12: 10-12 ; 15: 3-4 ; 16: 5-7 ; 19: 1-8$. Genoemde liederegedeeltes mag op historiese vlak sekere liturgiese elemente uit die tradisies reflekteer maar is funksioneel deel van ' $n$ narratiewe eindproduk wat die werk van een outeur is. Daarom dra dit ook funksioneel by tot die "Gestalt" van die dramatiese narratief as geheel.

\section{2.. Verdere metodologiese oorwegings}

Die toepassing van narratiewe perspektiewe op die liedere van Openbaring open bepaalde eksegetiese vergesigte en insigte maar is nie sonder metodologiese probleme nie. Een daarvan is die verhouding tussen die narratiewe elemente en die sosiale en historiese konteks. Die probleem is reeds aangeraak ${ }^{13}$ maar nog nie uitgeklaar nie. Adela Collins het byvoorbeeld 'n direkte lyn getrek tussen die sosiohistoriese konteks van die liedere in Openbaring, verwysende na die gemeentesituasie, en ' $n$ literêre analise van die teks self ${ }^{14}$. Die noodsaaklikheid van ' $n$ kennis van die historiese konteks mag nie ontken word nie. Die vraag is eerder hoe die betekenis van die teks vir die leser in verband gebring moet word met die sosiale en historiese konteks. Die eksklusiewe uitsluiting van die een of die ander faset verarm die finale eksegese.

Nicholas Lash worstel met dieselfde metodologiese vraag en stel dit so:

"... when we have to do with texts which speak of, and embody particular responses to fundamental aspects of the human predicament: questions of life and death, innocence and freedom, hope and suffering, then, in order to 'understand' those texts, the technical skills of the historian, although indispensable, are inadequate for the task"15.

Die teks van Openbaring 4-5 beantwoord aan dié beskrywing. Aangesien dit primêr ' $n$ religieuse teks is, is dit slegs histories te lees in sekondêre sin. Die sosiale en historiese kontekstuele inligting voorsien egter noodsaaklike reliëf. In die liedere volgens Openbaring is die narratiewe elemente gerekontekstualiseer deur middel van die narratiewe 
vorm om deel te geword het van die narratiewe wêreld. Openbaring kan juis as narratiewe teks ${ }^{16}$ beoordeel, die moderne leser dinamies aanspreek. Die betekenis van Openbaring 4-5 "... cannot be derived from its tradition but from its literary function in its present historical-literary context", aldus Schüssler-Fiorenza ${ }^{17}$. Anders gestel, die betekenis van dié liedere kan nie byeengebring word uit hulle pre-tekstuele geskiedenis nie maar moet gevind word in die funksie van die narratief in sy sosiale opset. Die funksie van die liedere in Openbaring 4-5 is ook om die leser te begelei na ' $n$ simboliese universum (narratiewe wêreld) wat die alledaagse sosiale werklikheid transformeer. In dié vertelde wêreld is die leser geborgde oorwinnaar saam met die Lam ten spyte van martelaarskap in die huidige bedeling. Op so ' $n$ wyse toegepas, kan die vraag ontstaan of die narratiewe eksegese nie wêreldontvlugting in die hand werk nie. Nee, deur literêre uitsigte wat lei tot eksistensiële insigte, kom juis wêreldbetrokkenheid.

Op 'n eklektiese wyse word gebruik gemaak van narratologiese insigte oor plotontwikkeling, vertellersperspektief en leserrespons. En bloot ter wille van die benoeming van die narratiewe eenhede word gebruik gemaak van kerne en satelliete. Kerne is die hoothandelinge wat die voortgang en ontvouing van die plot beskryf en satelliete is die narratiewe dele wat oorbly nadat die kerne afgebaken is. Satelliete help gewoonlik die leser om die kerne beter te verstaan ${ }^{18}$. Die kerne en satelliete in die plotontwikkeling moet ook gelees word teen die agtergrond van sekere kulturele of antropologiese inligting. Umberto Eco het dié verhouding tussen narratiewe funksies en kulturele inligting só omskryf:

"Certainly a plot can be seen as a series of functions, or a structured matrix of functions in alternate opposition, but the isolation of these functions cannot be freed from the preliminary attributions of pertinence (and therefore meaning) to each of these.... the functions of plot require value only when measured against the value systems of a given group" ${ }^{\prime 19}$.

Eco verduidelik sy standpunt aan die hand van die Griekse drama, wanneer Agamemnon sy Ifigenia moet offer. Vir ons Westerse gees is dit skokkend en onaanvaarbaar. In die narratief self is dit egter funksioneel. In die lig van die "vreemdsoortige" simboliek van Openbaring se taalgebruik, is dit 'n beginsel wat in ag geneem moet word. ' $n$ Analise van die kulturele kodes help die leser om die literêre funksies van die liedere in Openbaring beter te verstaan. Veral die etnologiese en mondelinge kulturele kodes, soos byvoorbeeld onder andere skande en eer, speel 'n funksionele rol.

\section{Hoofstukke 4 en 5 binne 'n groter narratiewe verband}

Indien aanvaar word dat ' $n$ Bybelse teks, soos in dié geval Openbaring, op historiese, strukturele en teologiese wyse geanaliseer kan word, is dit duidelik dat ' $n$ ideologiese vertellersperspektief ten opsigte van die narratief as geheel in ag geneem moet word in die bepaling van die betekenis van elke onderdeel daarvan. Die narratief van Openbaring wat as ' $n$ kunswerk beskryf kan word, word funksioneel tot 'n eenheid saamgebind deur die Christologiese melodie wat ' $n$ deurgaande ondertoon vorm ${ }^{20}$. Met in agneming van die funksionele rol van rekapitulasie (voortgang deur repetisie en interpretasie) en tussenvoegings (om saambinding te bewerk) kan op die vlak van simboliese optrede drie moontlike bedrywe in die dramatiese narratief onderskei word. In elke bedryf figureer die motief: God se voltrekking van verlossing en oordeel, en dit 
word op dramatiese wyse simbolies vertel. In bedryf 1 gee die opgestane en verheerlikte Christus sewe briefboodskappe aan die kerk (hoofstukke 1-3). Volgens bedryf 2 (hoofstukke 4-11) open die Lam die verseëlde boekrol waarvan die inhoud in die heelal ontplooi. In bedryf 3 is dit die draak en sy meelopers wat oorlog maak teen die Lam en sy navolgers in die loop van die geskiedenis (hoofstukke 12-22).

Volgens dié samehang funksioneer hoofstukke 4-5 as inleidende gedeelte tot die vertelling oor God se voltrekking van verlossing en oordeel in die heelal op grond van die rol van Lam volgens hoofstukke 4-11 21 . Hoofstukke 4-5 kan egter ook gelees word as sluitstuk van hoofstukke 1-5 $5^{22}$. Die funksionele rol en betekenis van hoofstukke 4-5 in die geheelopbou van Openbaring is in elk geval medebepalend vir die verstaan van die funksie van die liedere in dié twee hoofstukke.

Plotanalise beskryf die funksionele gebeure of narratiewe kerne en satelliete. Die liedere in hoofstukke 4 en 5 is nie as sodanig as kerne of satelliete te beoordeel nie maar maak deel uit van groter eenhede wat sodanig is. In sodanige opset het die liedere die funksie van narratiewe kommentaar. Dit kom veral na vore in Openbaring waar ons sowel herhaling van gebeure in die plot vind. Dit word rekapitulasie genoem ${ }^{23}$. Nie net wat sekere temas betref nie maar ook ten opsigte van verhaalelemente.

\section{Narratiewe analise van die liedere in Openbaring 4-5}

Narratiewe kommentaar is ' $n$ belangrike funksie van die verteller. Kommentaar kan betrek word op die verhaal (fabula) self of op die vertelling as sodanig. Op só 'n wyse kan die liedere in Openbaring die voortgang van die gebeure kommentarieer. Kommentaar, op sy beurt, kan die gestalte aanneem van interpretasie, beoordeling of 'n veralgemenende toepassing ${ }^{24}$.' $n$ Duidelike voorbeeld hiervan vind ons in Openbaring 1:20, waar op die sewe sterre en sewe boodskappers kommentaar gelewer word.

Die liedere in hoofstukke 4-5 funksioneer as implisiete kommentaar wat opkom uit die ideologiese vertellersperspektief van die verteller. Dié liedere word volgens dié vertelling in die hemel gesing, in die troonsaal van God, weg van die aarde waar die meeste narratiewe gebeure plaasvind. Dié ruimtelike verskil beskryf as sodanig reeds betekenis. En dit geld van al die liedere in Openbaring, behalwe 16:3-4. Op só 'n wyse kommentarieer die liedere in hoofstukke 4-5 die vertelde gebeure deur dit in ' $n$ betekenisvolle "hemelse" konteks te plaas. Die leser word onmiddellik betrokke in die kommunikatiewe situasie van die teks. Deur die liederekommentaar slaag die geïmpliseerde outeur daarin om die geimpliseerde leser van rigtinggewende kommentaar te voorsien ter wille van die regte perspektiewe op die vertelde gebeure. Op só 'n wyse slaag die verteller ook daarin om die leser te oortuig dat sy vertelling waar en eg en betekenisvol is. Die leser is daarom ook uitgelewer aan die geïnterpreteerde ethos van die verteller. Volgens hoofstuk 4 word aan die leser 'n raamwerk deur kommentaar voorsien dat God die skepper is en volgens hoofstuk 5 dat God die verlosser is.

Dit geld ook van fokalisasie of die vertellersperspektief van waaruit die vertelde vertel word. Kommentariëring handel oor die inhoud van die narratief en fokalisasie oor die wyse waarop of perspektief van waaruit die narratief vertel word ${ }^{25}$.

Die liedere in hoofstukke 4-5 word spesifiek afgebaken as 4:8-11 en 5:9-13. Die narratiewe kern waarbinne hoofstuk 4 figureer, is die van aanbidding in die hemelhof. Die troonkamer van God in die hemel bepaal die situering van die vertelling in hoofstuk 
4. Johannes vertel volgens sy perspektief wat hy sien en hoor. Hy is die fokaliseerder van die vertelde gebeure, met ander woorde, die leser "kyk" deur Johannes se bril na dié aangrypende toneel. Dit is egter nie ' $n$ tipiese subjektiewe situasie van 'n eerstepersoon fokaliseerder-verteller nie maar gekontroleerd omdat die vertelling volgens 1:1 "deur Jesus Christus geopenbaar is". Johannes is dus 'n "verteller-karakter" 26 .

Johannes sien "lemand wat op die troon sit" (4:2); asook vier en twintig ouderlinge en vier lewende wesens wat ook op trone sit. Dit beskryf die eerste van vier teofanieë in Openbaring ( $\mathrm{vgl}$ ook 8:5; 11:19 en 21:18-21). Volgens die taalgebruik herinner dié gesig aan die Sinaï-teofanie (Eks 19:6) asook die strydvariasie van Esegiël (Eseg 1:13). Hierdie teofanie, volgens die nuwe funksionele aanwending in die narratief, beklemtoon die feit dat God sal kom om te oordeel. Die vier lewende wesens, die arend, bul, leeu en mens verteenwoordig God se skepping en die vier en twintig ouderlinge die Christene.

Die lewende wesens hef hulle lied aan:

"Heilig, heilig, heilig is die Here God, die Almagtige, Hy wat was en wat is en wat kom". Opvallend dat die sanctus ("heilig, heilig, heilig"), geneem uit Jesaja 6:3, nie kommentaar lewer op God se dade in die verlede nie maar eerder op sy persoon en wese. Die aanhef tot die lied ontstaan nie in ' $n$ vakuum nie. Deur intertekstualiteit, in hierdie geval met 'n godsdienstige tradisie, word 'n bestaande teks in Jesaja eintlik "herskryf". Die beklemtoning van die heiligheid van God in die aanvang van die lied funksioneer juis om die grootheid en andersheid van God te aksentueer. Ook sy almagtigheid word gekontrasteer met die pretensieuse magvertoon van aardse bewindhebbers. Die leser is onmiddellik in die sfeer van die heelal ingetrek. Die weglating van die tweede deel van Jesaja 6:3: "Die hele aarde is vol van sy almagtige teenwoordigheid" deur die verteller, sinspeel op die verdorwenheid van die vertelde wêreld van Johannes. Die narratiewe funksie van dié strofe deur die lewende wesens is juis om aan die leser te sê dat die wêreld van Openbaring verdorwe is en nie die goedheid van God se skepping reflekteer nie. Dat Hy "wat was en wat is" kom (ergómenos) benadruk dat God onafwendbaar oppad is met sy verlossing en oordeel.

In 4:9 is ook sprake van ' $n$ lied. Ons lees dat die lewende wesens "heerlikheid, eer en dank toebring aan Hom wat op die troon sit ...". Dit herinner aan 5:13 alhoewel ons nie beskik oor die presiese bewoording van die moontlike lied nie ${ }^{27}$. Die narratiewe funksie van die weglating van die direkte bewoording is waarskynlik om nie die narratiewe gang van die res van die opbou van hoofstuk 4 te versteur nie. Dit dien daarom net as inleiding tot die lied deur die vier en twintig ouderlinge (4:10):

"Here, ons God, $U$ is waardig om die heerlikheid en die eer en die mag te ontvang omdat $u$ alles geskep het; deur $u$ wil het alles ontstaan en is dit geskep".

Dié lied vorm ' $n$ antifoniese antwoord op die liedere in $4: 8-9$ en voorsien die pertinente rede waarom God waardig is om geprys te word, sowel as die motivering waarom God oordeel kan vel oor die aarde. Die lied is direk (vgl tweede persoon ekv. van eimi) aan God gerig. Omdat God die skepper is, staan alles onder sy jurisdiksie. Die funksie van die lied is om die leser te vergewis van die ware identiteit van God, naamlik sy mag en heerlikheid en beheer oor die heelal op grond daarvan dat Hy geskep het. In die Mediterreense kulturele milieu het die klem grotendeels op eer/oneer geval ${ }^{2 \dot{8}}$. Dit is God wat die eer van die regverdiges sal uitbring en die goddeloses sal straf. God is die weldoener. Daarom besing die wesens God se wese. Die narratiewe funksie van die liedere in hoofstuk 4 is interpretatief. Die aard en wese van Hom wat op die troon 
sit word geïnterpreteer as die skepper. Van Hom kan nog veel verwag word in die res van die narratief!

Die fokalisasie in die direkte rede (4:11) skep die indruk van onmiddellikheid, tot só 'n mate dat die lesers/hoorders dit beleef dat hulle deel is van die vertelde wêreld. Dit word 'n "enacted or focused scene", volgens Funk "which allows the reader to see, hear, and upon occasion taste, touch, feel, what transpires, as nearly as words will create that illusion" ${ }^{29}$. Die leser het 'n aanduiding ontvang van wat God nog gaan doen (4:119).

Die ideologiese vertellersperspektief kom dikwels tot uitdrukking deur die gebruik van eiename. God is die Een wat was; die Een wat is; die Almagtige en die Een wat kom. Dit is nie bloot name nie maar omskrywings van God se wese asook van die ideologiese vertellersperspektief van die vier lewende wesens. Hulle bring eintlik tot uitdrukking dat God ingelig moet word oor die toestand van die heelal. Dit is nie vol van sy heerlikheid en goedheid nie (4:8). Daarteenoor besing die vier en twintig ouderlinge juis God se heerlikheid en mag omdat Hy alles geskep het. Die uitdrukking dat die vier en twintig ouderlinge hulle krone voor God se troon neersit $(4: 10)$, voorafgegaan deur die narratiewe kommentaar dat God tot in alle ewigheid lewe, dien om die leser opwindend betrokke te kry.

Volgens die narratiewe kern van hoofstuk 5 sien Johannes 'n boekrol in die regterhand van God. Dit is alkant verseël met sewe seëls. In die situering word die problematiek dan gedefinieer deur die "sterk engel" wat roep na iemand waardig om die boekrol oop te maak (5:2). Nie iemand sterk, magtig of invloedryk, volgens aardse maatstawwe nie. Die begrip "waardig" (axios) skep onmiddellik leserbetrokkenheid asook verwagting. Die feit dat Johannes huil toe niemand gevind word nie (5:4), teken die eksterne psigologiese vertellersperspektief van die fokaliseerder. Johannes wil bittergraag die boekrol oopgemaak hê sodat die bose demonstratief oorwin moet word. Die veroweraar sal "waardig" wees om die boekrol oop te maak. Volgens die ouderlinge is dit die "Leeu uit die stam van Juda" (5:5) - 'n tipiese Messiaanse antwoord! ${ }^{30}$.

Teenoor die ouderlinge se Leeu van Juda en Afstammeling van Dawid sien Johannes, die fokaliseerder, 'n geslagte Lam. Die leser word gekonfronteer met die twee interpretasies oor Jesus se persoon - die veroweraar en die geslagte. Die leser/hoorder word betrokke om self die betekenis van "waardig" te vind. Na die verskyning van die antwoord, verrig die vier lewende wesens (skepping) en vier en twintig ouderlinge (Christene) 'n priesterlike funksie met die "goue bak vol wierook" (5:8).

Die lied in 5:9-10 besing die antwoord op die vraag in 5:2: "Wie is waardig om die boek oop te maak?" En die vermelding van die geslagte lam (arnion) (5:9) roep die paaslam en eksodusmotiewe na vore. Die loskoop van mense deur die bloed van die geslagte (5:9) sinspeel op die politieke loslating van oorlogsgevangenes. Dit pas goed in by die eksodusmotiewe sowel as die breër agtergrond van stryd tussen die Goddelike magte en die bedreigers van die gelowiges. Van Unnik het insiggewend aangetoon dat "waardig" iemand beskryf wat die toets van lyding en dood geslaag het ${ }^{3 T}$. Die dood van die Weldoener, die Lam, het verreikende gevolge vir die toekoms - die gelowiges "sal oor die aarde regeer" (5:10). Moontlik sinspeel dié uitdrukking op 20:4-5 en 21:27. Die volgende lied in 5:12 is ' $n$ antifoniese antwoord op die een in 5:9. Hierdie keer is dit ' $n$ "groot menigte engele" wat uitroep: "Die Lam wat geslag was, is waardig om die mag en rykdom, die wysheid en sterkte, die eer, heerlikheid en lof te ontvang" (5:12). Die fokus val weer eens op die "waardigheid" van die Lam. Die direkte tweede persoon 
aanspreekvorm is nou verruil vir 'n derde persoon onpersoonlike aanslag. Die rede vir die "waardigheid" van die Lam (geslag) word nie meer besing nie maar die resultaat vir die Lam self - die ontvangs van eer en lof.

En in 5:13 kommunikeer die verteller ' $n$ slotlied as sluitstuk vir hoofstukke 4-5. Dit word aangehef deur die hele skepping en nie net tot God of die Lam gerig nie maar tot albei. Die funksie van die slot-"amen" is veelseggend, indien die betekenis van "amen" in die apokaliptiese literatuur in ag geneem word. Schiller stel dit so:

"It was the confession of the praise of God which was laid on the community and which the community was to affirm by its answer. And it was the confession of the blessing of God which was pronounced to the community and which the community was to make operative by its Amen ...."32.

In vier van die vyf liedere in hoofstukke $4-5$, naamlik $4: 9,11 ; 5: 12,13$ word die eer en heerlikheid van die Lam en van God besing. Hulle is "verheerlikbaar", om dit só te stel, omdat Hulle die vyande van die gelowiges beskaam het. Die gelowiges het hulle stryd en saak na 'n groter "krag" geneem as gevolg van eie onvermoë, naamlik God en die Lam, volgens die narratiewe simboliese universum. Volgens die vertelling in hoofstukke 4-5 het God dié uitdaging "aanvaar" deur die Lam se offer, en op grond daarvan het Hy oorwin en die saak van die gelowiges besleg.

Veral die lied in 5:9 is ' $n$ sprekende voorbeeld van narratiewe interpretatiewe kommentaar. Dié kommentaar gee die redes aan waarom die Lam "waardig" is om die boekrol oop te maak. Deur assosiasie word ook ' $n$ verband geplaas tussen martelaarskap en die inhoud van die boekrol.

Die fokalisering volgens hoofstuk 5 is effektief gedoen op die lippe van verskillende karakters. Die verwysing na die slagting van die Lam kan ook indirekte intertekstualiteit genoem word. Die leser word deur die liedere funksioneel in ' $n$ ideologiese raamwerk geplaas, naamlik die sterwe van Jesus Christus en die effek en betekenis daarvan. Op so ' $n$ wyse word die eksistensiële betrokkenheid van die leser/hoorder verhoog.

Die verhaal van die narratief volgens hoolstukke $4-5$ begin by die skepping om te illustreer met Wie ons te doen het; verder fokus dit op Jesus se dood en eindig dan met die kulminasie van die koninkryk in hoofstukke 21-22. Gedurende die tussentyd, dit wil sê wanneer die gelowiges vervolg word, moet hulle rus vind in die voortyd van die narratief, naamlik dat die Een in wie hulle glo as verlossingoffer geslag is en kan hulle hul ook reeds verlustig in die geborgde toekoms wanneer hulle as "' $n$ koninkryk en priesters vir God" oor die aarde sal regeer (5:10).

Hoofstukke 4-5 het ' $n$ reeks onderwerpe op die tafel geplaas waaromheen die plot van die vertelling nog gaan ontwikkel. Volgens die narratief is die identiteit van God en die Lam volgens dié liedere reeds uitgewys, op só ' $n$ wyse dat leserbetrokkenheid verkry is. God word deurgaans besing en vertel as die Almagtige Een wat met krag kom om te oordeel. Die voorstelling van Jesus is tweeledig. Aan die een kant is Hy die Messiaanse Seun van die mens ("Lam van Juda": 5:5) wat kom om te oordeel (vgl $14: 14-20 ; 19: 11-21$ ) en aan die anderkant is Hy die Lam wat vrywillig geslag is ter wille van verlossing.

Die gelowiges is volgens die himniese narratief verseker van God se instaan vir hulle op grond van sy skeppings- en verlossingsmag. En op grond van sy verlede is hulle hede en toekoms respektiewelik betekenisvol en geborg. 
1. Vgl. F Kermode, "Introduction to the New Testament" in The Literary guide to the Bible (Edited by R Alter and F Kermode), London: Collins 1987, 375-386; JA du Rand, Johannese perspektiewe, deel 1: Inleiding tot die Johannese geskrifte, Pretoria: 1990, 180-182; MA Harris, The literary function of hymns in the Apocalypse of John, Ann Arbor: 1988, 29.

2. AY Collins, Crisis and Catharsis: The power of the Apocalypse, Philadelphia: 1984, 84-110; E Schüssler Fiorenza, The Book of Revelation: Justice and judgement, Philadelphia: 1985, 181-204.

3. Vgl. bv. Schüssler-Fiorenza, a.w., 166; J Blevins, "The genre of Revelation", Rev Exp 77 (1980), 397.

4. Vgl. verder sy Urchristentum und Gottesdienst, 4 Aufl., Tübingen: Mohr 1962, 9.

5. DL Barr het dié aspek veral na vore gebring in sy "The Apocalypse of John as oral enactment", Interp 40 (1986), 252-256. Vgl. ook D Aune, "The Apocalypse of John and the problem of genre", Semeia 36 (1986), 80-81.

6. Vgl. in die verband MH Shepherd, The Paschal liturgy and the Apocalypse, Richmond: 1960; P Prigent, Apocalypse et Liturgie, Neuchatel 1964; S Laüchli, "Eine Gottesdienststruktur in der Johannes offenbarung. ThZ 16 (1960), 359-278.

7. Aldus DR Carnegie, "Worthy is the Lamb: The hymns in Revelation", in Christ the Lord: Studies in Christology (presented to D Guthrie and edited by H Rowdon), Leicester: IVP 1982, 246-247. Net só D Aune, The New Testament in its literary environment, Philadelphia: $1987,43$.

8. Hy onderskei 30 liedere in Openbaring: Revelation as drama, Nashville: 1984, 19vv.

9. R Brewer, aangehaal deur JR Bowman, The first Christian drama, Philadelphia: 1955, 67v.

10. MA Harris, a.w., 8; vgl. S Rimmon-Kenan, Narrative fiction: Introduction to poetics, London: 1983, 106.

11. Aldus Schüssler-Fiorenza, a.w., 166-167.

12. Vgl. K-P Jörns, Das hymnische Evangelium: Untersuchungen zu Aufbau, Funktion und Herkunft der hymnische Stücke in der Johannesoffenbarung, Gütersloh: 1971, 15-19.

13. Vgl. bv. N Petersen, Literary criticism for New Testament critics, Philadelphia: 1978, 11-23.

14. A Collins, a.w., 86 .

15. Kyk sy "What might martyrdom mean?", Ex Auditu 1 (1985), 17, 14-29.

16. Vgl. Mieke Bal se beskrywing van die teks van Openbaring as "a text in which an agent relates a narrative" (Narratology, Toronto: 1985, 7). Kyk ook W Kelber, "Gospel narrative and critical theory", BThB 18 (1988), 130.

17. E Schüssler-Fiorenza, a.w., 22. 
18. Vgl. die teoretiese uiteensetting hiervan deur $\mathrm{R}$ Barthes, "Introduction to the structural analysis of narrative, in A Barthes Reader (ed. S Sontag), New York: Hill \& Wang 1982, 251-295.

19. Kyk sy $A$ theory of semiotics, Bloomington: 1979,145 . Vgl. ook MA Harris, a.w., 27-28.

20. Vgl. Du Rand, a.w., 266.

21. Kyk L Hurtado, "Revelation 4-5 in the light of Jewish Apocalyptic analogies, JSNT 25(1985), 105-124.

22. Alhoewel dit 'n ongewone interpretasie is, word dit sterk gesteun deur MA Harris, a.w., $31 \mathrm{w}$.

23. Vgl. B McGinn, "Revelation" in The literary guide to the Bible (Edited by F Kermode; A Alter) Cambridge, Mass.: 1987, 523-541.

24. Vgl. S Chatman, Story and discourse, Ithaca: 1978, 237-248.

25. Kyk verder oor fokalisasie en vertellersperspektief, veral die tegniese verskil tussen die begrippe, M Bal, a.w., 100-102. G Genette het die term fokalisasie gemunt. Vgl. Narrative discourse: An essay in method. Trans. J Lewin, Ithaca: 1980, 189-211.

26. Aldus F Stanzel, "Teller-characters and reflector-characters in narrative theory", Poetics Today vol 2,2 (1981), 1-10, spesifiek 6.

27. Jörns, a.w., 67-70, het vindingryk probeer om dié lied in 4:9 te herkonstrueer.

28. 'n Mens sou ook ander attribute kon uitsonder. Eer/oneer speel 'n dominante rol, oortuigend aangetoon deur B Malina, New Testament world: insights from cultural authropology, Atlanta: $1981,27,38$.

29. Vgl. R Funk, a.w., 32-34.

30. Kyk J Roloff, Die Offenbarung des Johannes, Zurich: 1984, 74.

31. Vgl. WC van Unnik, "Worthy is the Lamb: the background of Apoc 5", in: Melanges bibliques en hommage au RP Beda Rigaux, ed. A Descamp; RP Andre de Halleux). Paris: 1970, 449.460 (Spesifiek 456-457).

32. Theologisches Wörterbuch zum Neuen Testament, Vol 1, 334. 